\title{
Sự thay đổi hoạt động giảng dạy môn học của giảng viên dưới góc nhìn phản hồi từ người học
}

\author{
(Nghiên cứu tại Trường Đại học Sài Gòn)
}

\author{
Lê Chi Lan*, Đỗ Đình Thái \\ Trường Đại hoc Sài Gòn, 273 An Dương Vuoong, \\ Quận 5, Thành phố Hồ Chí Minh, Việt Nam \\ Nhận ngày 10 tháng 2 năm 2017 \\ Chỉnh sửa ngày 20 tháng 4 năm 2017; Chấp nhận đăng ngày 20 tháng 6 năm 2017
}

\begin{abstract}
Tóm tắt: Giáo dục đại học đóng vai trò cung cấp những kiến thức và kỹ năng cho sinh viên tham gia vào thị trường lao động. Chất lượng giáo dục đã trở thành một đề tài nóng bỏng đối với nhiều cá nhân và các tổ chức có liên quan. Trong giáo dục đại học hoạt động giảng dạy của giảng viên đóng một vai trò quan trọng. Hiện nay, theo quy định của Bộ GD \&ĐT các trường đại học chuyển dần sang việc đào tạo theo học chế tín chỉ việc đổi mới hoạt động giảng dạy theo yêu cầu của học chế tín chỉ "Lấy người học làm trung tâm" là điều không thể thiếu. Trong nghiên cứu tìm hiểu sự phản hồi của người học về phương pháp giảng dạy, về quá trình giảng dạy và học tập và chất lượng của quá trình đào tạo. Qua đó có thể thấy những mong mỏi của người học về quá trình đào tạo.
\end{abstract}

Tù khóa: Sự hài lòng, người học, hoạt động giảng dạy môn học, giảng viên.

\section{Mở đầu}

Trong xu thế hội nhập và phát triển, ngành giáo dục luôn được quan tâm hàng đầu, nhất là chất lượng giáo dục đại học. Để từng bước phát triển giáo dục đại học theo chuẩn quốc tế, Bộ Giáo dục và Đào tạo đã ban hành Quyết định số 65/2007/QĐ-BGDĐT ngày 01 tháng 11 năm 2007 về việc ban hành Quy định về tiêu chuẩn đánh giá chất lượng giáo dục trường đại học. Chất lượng giáo dục đã trở thành một đề tài nóng bỏng đối với nhiều cá nhân và các tổ chức có liên quan. Trong giáo dục đại học bên cạnh việc sinh viên phải nổ lực học tập thì hoạt động giảng dạy của giảng viên cũng đóng một vai trò quan trọng không kém [1]. Trước đây, giáo dục

\footnotetext{
Tác giả liên hệ. ĐT.: 84-908227743.

Email: chilansgu.kt@gmail.com

https://doi.org/10.25073/2588-1159/vnuer.4082
}

được xem như một hoạt động sự nghiệp đào tạo con người mang tính phi thương mại, phi lợi nhuận nhưng qua một thời gian dài chịu sự ảnh hưởng của các yếu tố bên ngoài, đặc biệt là tác động của nền kinh tế thị trường đã khiến cho tính chất của hoạt động này không còn thuần túy là một phúc lợi công mà dần thay đổi trở thành "dịch vụ giáo dục". Theo đó, giáo dục trở thành một loại dịch vụ và khách hàng (sinh viên, phụ huynh) có thể bỏ tiền ra để đầu tư và sử dụng một dịch vụ mà họ cho là tốt nhất. Hiện nay, theo quy định của Bộ GD \&ĐT các trường đại học chuyển dần sang việc đào tạo theo học chế tín chỉ, đây là hình thức đào tạo còn mới đối với một số trường đại học, việc đổi mới hoạt động giảng dạy theo yêu cầu của học chế tín chỉ "Lấy người học làm trung tâm" là điều không thể thiếu. Tuy nhiên, có những câu hỏi liên quan đến tính hiệu quả của việc đổi mới 
này có đáp ứng mong đợi từ phía người học hay không vẫn còn là câu hỏi chưa có lời giải đáp và nhất là đang trong giai đoạn áp dụng đào tạo theo học chế tín chỉ. Xuất phát từ lý do trên, chúng tôi chọn đề tài nghiên cứu: Sự thay đổi trong hoạt động giảng dạy của giảng viên dưới góc nhìn phản hồi từ người học. Do khuôn khổ thời gian nên nhóm tác giả chỉ chọn một số ngành có số lượng đào tạo đông sinh viên như: ngành Sư phạm Tiểu học, ngành Sư phạm Mầm non, ngành Công nghệ Thông tin, ngành Kế toán và ngành Quản trị Kinh doanh tại trường Đại học Sài Gòn để nghiên cứu và phân tích.

\section{Các nghiên cứu có liên quan đến sự phản hồi của người học}

Hình thức sinh viên đánh giá hoạt động giảng dạy của giảng viên và chất lượng đào tạo cũng như nhiều lĩnh vực khác của nhà trường đã được tiến hành từ rất lâu và phát triển qua nhiều thời kỳ khác nhau trên thế giới. Đây là hình thức được sử dụng phổ biến và thường xuyên trong giáo dục đại học Hoa Kỳ, Châu Âu, Úc và các nước Châu Á như Nhật Bản, Singapore, Thái Lan... Ngay từ thời kỳ Trung cổ, các trường đại học ở Châu Âu dựa vào sinh viên để kiểm tra việc giảng dạy của giảng viên. Hiệu trưởng thành lập một Hội đồng sinh viên có nhiệm vụ ghi chép xem giảng viên có giảng dạy theo đúng lịch trình giảng dạy quy định của trường không, nếu có sự thay đồi nào ngoài quy định chung sẽ báo cáo ngay cho Hiệu trưởng. Hiệu trưởng sẽ có hình thúc xử lý giảng viên về những vi phạm đó. Thời kỳ Thực dân vào thế kỷ thứ XVI và XVII, cuối năm học đại diện Hội đồng quản trị và Hiệu trưởng dự giờ quan sát việc giảng viên đặt câu hỏi kiểm tra kiến thức cả năm học của sinh viên trên cơ sở đánh giá hoạt động giảng viên [6].

Trong giai đoạn từ năm 1925-1960 các trường đại học và cao đẳng xây dựng và sử dụng bảng đánh giá chuẩn dùng cho sinh viên đánh giá giảng viên và bản thân giảng viên các trường đại học và cao đẳng đã nhận thức rõ mục đích và ý nghĩa của bảng đánh giá giảng dạy và đã tình nguyện sử dụng bảng đánh giá chuẩn với mục đích cải tiến và điều chỉnh việc giảng dạy của mình trên cơ sở phân tích các kết quả thu được của bảng đánh giá [7]. Từ những năm 1970, ngày càng có nhiều trường đại học và cao đẳng sử dụng các bảng đánh giá chuẩn. Trên thế giới, đã có nhiều công trình nghiên cứu về việc sinh viên đánh giá giảng viên. Hầu hết các chuyên gia đều đánh giá cao giá trị ý kiến phản hồi từ sinh viên. Trong lĩnh vực nghiên cứu về đánh giá chất lượng giảng dạy thì Terry D.Buss (1976) đã nghiên cứu sự cần thiết phải lấy ý kiến đánh giá của sinh viên về chất lượng giảng dạy của giảng viên. Kết quả cho thấy hầu hết các trường đại học ở Hoa Kỳ đã sử dụng đánh giá người học để cải tiến chất lượng giảng dạy và nội dung chương trình đào tạo [9]. Theo nghiên cứu của Bộ Giáo dục Mỹ năm 1991 dựa trên khảo sát của 40.000 giảng viên đại học thì $97 \%$ các giảng viên cho rằng cần sử dụng đánh giá của sinh viên để kiểm tra công tác hoạt động giảng dạy. Gibbs (1995) kết luận là ý kiến của sinh viên đang ngày càng được sử dụng nhiều ở Anh, Ramsden cũng đưa ra kết luận tương tự trong báo cáo của một nghiên cứu ở Australia năm 1993 [8]. Điểm mạnh của các nghiên cứu trên là nghiên cứu về mức độ thay đổi đối với công tác giảng dạy và chỉ ra tác động của việc hài lòng này trong việc nâng cao chất lượng giảng dạy. Các nghiên cứu còn chỉ ra được giảng viên dạy các môn khoa học xã hội thường được sinh viên đánh giá cao hơn so với các giảng viên dạy các môn khoa học tự nhiên. Sinh viên các lớp sau đại học thường đánh giá giảng viên cao hơn so với các sinh viên bậc đại học. Những môn học tự chọn được sinh viên đánh giá cao hơn các môn học bắt buộc. Giảng viên dạy các lớp nhỏ thường được sinh viên đánh giá cao hơn so với giảng viên lớp đông [9].

Ở Việt Nam đã có rất nhiều nghiên cứu về vấn đề sự thay đổi về hoạt động đào tạo tại một số trường đại học như: Nghiên cứu sự hài lòng của sinh viên đối với hoạt động đào tạo tại Đại Học Khoa Học Tự Nhiên - đại học Quốc Gia TP HCM (Nguyễn Thị Thắm, 2010); Đánh giá sự hài lòng của sinh viên về chất lượng đào tạo 
tại Trường Đại học Kinh tế và Quản trị kinh doanh Thái Nguyên (Trần Xuân Kiên, 2006); Sự hài lòng của sinh viên trường đại học công nghiệp với chất lượng đào tạo (Đặng Mai Chi, 2007); Các yếu tố ảnh hưởng đến sự hài lòng của sinh viên đối với cơ sở vật chất, trang thiết bị tại Trường Đại học Đà Lạt (Ma Cẩm Tường Lam, 2011). Ngoài ra, tác giả Trần Thị Tú Anh (2008) đã nghiên cứu đánh giá chất lượng giảng dạy đại học tại Học viện Báo chí và Tuyên truyền" [3]. Qua các nghiên cứu cho thấy những nghiên cứu về sự hài lòng của sinh viên về chương trình đào tạo, cơ sở vật chất ... được thực hiện cả trên thế giới cũng như ở Việt Nam. Hầu hết các nghiên cứu đều khẳng định rằng sinh viên là nhân tố đóng vai trò quan trọng trong việc khẳng định chất lượng của một trường đại học, bên cạnh vấn đề nghiên cứu sự thay đổi về chất lượng đào thì chúng tôi cho rằng vấn đề cần xem xét thêm đó là sự thay đổi hoạt động của giảng viên đã thay đổi như thế nào khi các trường đại học đã thực hiện công tác lấy ý kiến phản hồi của người học, việc nghiên cứu này có giá trị và là một nguồn thông tin hết sức bổ ích và cần thiết cho việc nâng cao chất lượng đào tạo...

\section{Mô hình nghiên cứu thay đổi hoạt động giảng dạy của giảng viên}

Theo quy định của Bộ GD\&ĐT các trường đại học chuyển dần sang việc đào tạo theo học chế tín chỉ, việc đổi mới hoạt động giảng dạy theo yêu cầu của học chế tín chỉ "Lấy người học làm trung tâm" là điều không thể thiếu.

+ Việc chuẩn bị nội dung giảng dạy của giảng viên là điều rất cần thiết và đóng vai trò quyết định chất lượng giảng dạy môn học của người giảng viên. Việc chuẩn bị nội dung giảng dạy bao gồm: tài liệu học tập, cách thức và tiêu chí kiểm tra đánh giá, mục tiêu giảng dạy...

+ Phương pháp giảng dạy (PPGD) là một thành tố hết sức quan trọng của hoạt động giảng dạy. Trong giảng dạy nếu giảng viên sử dụng các phương pháp dạy học tích cực là phát triển khả năng sáng tạo, tư duy độc lập của người học thì sẽ phát huy cao năng lực người học.
PPGD của giảng viên thực sự có hiệu quả khi người học được hướng dẫn tự học, tự nghiên cứu và trong quá trình giảng dạy và học tập giảng viên sử dụng tốt các phương tiện hỗ trợ giảng dạy.

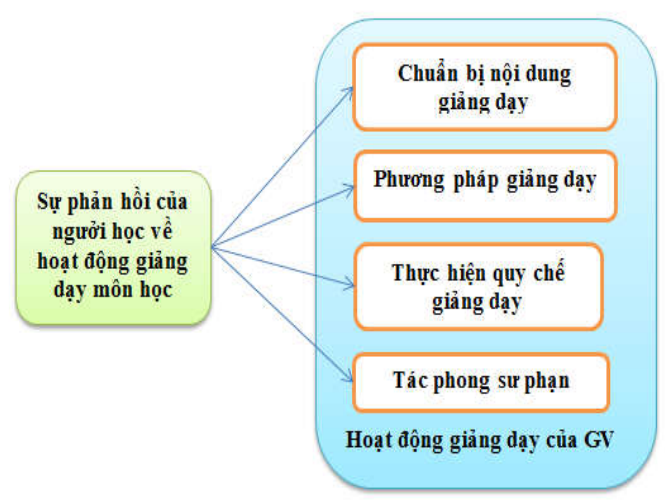

Hình 1. Khung lý thuyết nghiên cứu về sự thay đổi hoạt động giảng dạy môn học theo ý kiến phản hồi của sinh viên.

+ Hoạt động giảng dạy có hiệu quả còn được thể hiện qua việc thực hiện tốt quy chế giảng dạy như: giảng viên phải đảm bảo giờ lên lớp, thực hiện đúng và đủ số tiết quy định, thực hiện kiểm tra, đánh giá khách quan và đúng quy chế.

+ Tác phong sư phạm của giảng viên thể hiện qua trang phục chỉnh tề, sự nhiệt tình, trách nhiệm, lắng nghe ý kiến người học sẽ tạo nên sự tương tác tốt giữa giảng viên và người học. Cách tổ chức và quản lý lớp học tốt sẽ làm tăng hiệu quả hoạt động giảng dạy của giảng viên.

Vì vậy, dưới góc nhìn của người học thì hoạt động giảng dạy của giảng viên đã có sự thay đổi như thế nào. Câu hỏi nghiên cứu đặt ra là sinh viên đánh giá như thế nào về sự thay đổi hoạt động giảng dạy môn học của giảng viên? Sự thay đồi hoạt động giảng dạy của giảng viên có đáp ứng được sự mong đợi của người học không? Trong giới hạn nghiên cứu của đề tài sự phản hồi của người học về hoạt động giảng dạy của giảng viên được xem xét ở 3 khía cạnh: (1) Chuẩn bị nội dung giảng dạy; (2) Phương pháp giảng dạy; (3) Thực hiện quy chế giảng dạy và tác phong sư phạm. 


\section{Quy trình và thiết kế nghiên cứu}

Nghiên cứu kết hợp cả phương pháp nghiên cứu định tính và định lượng và được tiến hành 2 bước chính (hình 2): Nghiên cứu sơ bộ và nghiên cứu chính thức.

Trên cơ sở thăm dò ý kiến từ phía chuyên gia, cán bộ quản lý và giảng viên, nghiên cứu tiến hành xây dựng phiếu khảo sát ý kiến có liên quan đến sự phản hồi của người học trong hoạt động giảng dạy của giảng viên. Nhóm tác giả tiến hành điều tra thử nghiệm sau khi đã xây dựng phiếu khảo sát để kiểm tra độ tin cậy và độ giá trị của phiếu khảo sát, trên cơ sở đó chỉnh sửa các câu hỏi chưa đạt yêu cầu. Mẫu điều tra thử nghiệm là 60 sinh viên. Tiến hành điều tra khảo sát chính thức. Phương pháp chọn mẫu khảo sát cho người học, dung lượng mẫu: 526 người. Cách chọn: chọn ngẫu nhiên phân cụm theo tỷ lệ phần trăm người học thuộc các ngành Sư phạm và ngoài sư phạm từ 5 ngành đại diện có số lượng sinh viên đào tạo khá đông.

Các biến số và dữ liệu liên quan:

- Biến độc lập: sự chuẩn bị nội dung giảng dạy, phương pháp giảng dạy; thực hiện quy chế giảng dạy và tác phong sư phạm.

- Biến phụ thuộc: sự phản hồi của sinh viên.

- Biến kiểm soát: khóa học, ngành học, xếp loại học tập, giới tính.

Dữ liệu liên quan: Các dữ liệu về ý kiến phản hồi của người học về hoạt động giảng dạy học các năm học 2013 - 2014, 2014 - 2015 và $2015-2016$.

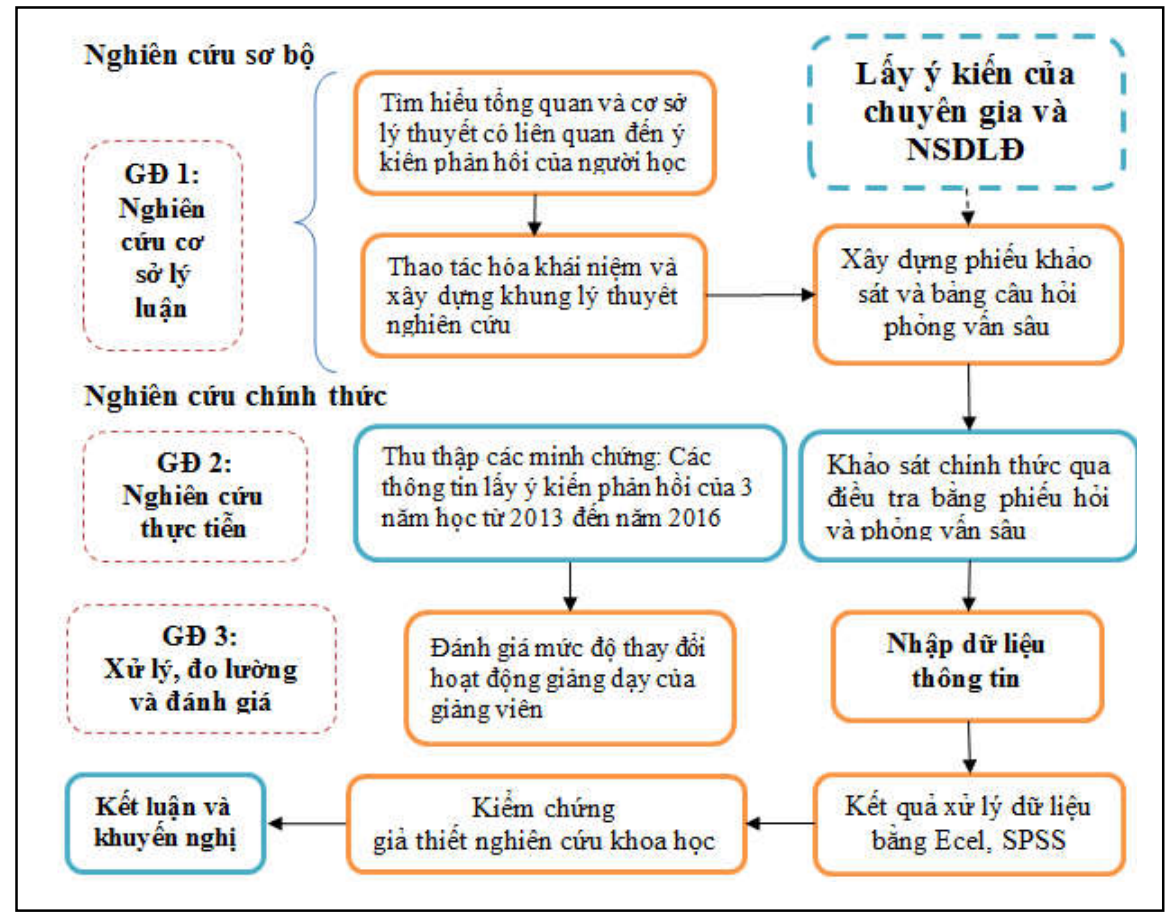

Hình 2. Quy trình nghiên cứu sự thay đổi hoạt động giảng dạy của giảng viên.

\section{Quy trình chọn mẫu}

- Chọn mẫu để khảo sát bằng bảng hỏi: Trường đại học Sài Gòn hiện tại có 33 ngành cấp độ đại học, tuy nhiên nhóm tác giả chỉ chọn ra 5 ngành đại diện: ngành Sư phạm Mầm non, ngành Sư phạm Tiểu học, ngành Công nghệ Thông tin, ngành Kế toán, ngành Quản trị Kinh doanh. Các ngành này có số lượng sinh viên đào tạo khá đông. Mẫu được chọn theo phương pháp ngẫu nhiên. Mỗi ngành trên chọn ra 30 50 sinh viên trải đều từ năm thứ nhất đến năm 
thứ tư (tương đương khóa 2013, 2014, 2015 và 2016). Tổng cộng, sẽ có tất cả 526 sinh viên của 5 ngành trên tham dự điều tra khảo sát.

- Chọn mẫu để phỏng vấn sâu: Mỗi khóa học chọn ngẫu nhiên 2 sinh viên của 5 ngành được khảo sát, do đó sẽ có tất cả 10 sinh viên tham gia phỏng vấn sâu. Các sinh viên này có sự khác nhau về giới tính, hộ khẩu thường trú trước khi nhập trường và khác nhau về kết quả học tập.

\section{6. Đánh giá mức độ thay đổi hoạt động giảng dạy của giảng viên}

Để nghiên cứu sự thay đổi trong hoạt động giảng dạy môn học của giảng viên, chúng tôi đã tiến hành khảo sát mẫu ở 4 ngành đại diện: Khoa Sư phạm Khoa học xã hội (ngành Ngũ Văn, Lịch sử, Địa lý) số lượng: 118 chiếm tỷ lệ: 22.4\%, ngành Giáo dục Chính trị (số lượng: 103 chiếm tỷ lệ: $19.6 \%$, ngành Công nghệ Thông tin số lượng: 168 chiếm tỷ lệ: $31.9 \%$, ngành Sư phạm Tiếng Anh (số lượng: 137 chiếm tỷ lệ: 26.0\%), Mẫu được chọn theo phương pháp ngẫu nhiên, phân tầng và theo cụm. Tổng số phiếu phát ra là 650 , thu vào 545 phiếu và sau khi nhập dữ liệu có 526 hợp lệ chiếm tỷ lệ 80,9\%.

Việc thiết kế bảng hỏi với những thang đo lường có độ tin cậy là rất quan trọng. Tổng cộng phiếu khảo sát có 16 câu hỏi được thiết kế để tìm hiểu sự phản hồi của người học về hoạt động giảng dạy của giảng viên. Sau khi tiến hành phát và thu phiếu hỏi về, nhóm nghiên cứu chúng tôi đã tiến hành mã hóa các dữ liệu trên thang đo 5 mức, được tính với số điểm như sau: chưa tốt $=1$ điểm; bình thường $=2$ điểm; khá $=$ 3 điểm và tốt $=4$ điểm; rất tốt $=5$ điểm. Để đánh giá độ tin cậy của thang đo của phiếu hỏi, nhóm chúng tôi đã tiến hành sử dụng công cụ Crobach Alpha, kết quả Crobach Alpha bằng 0.840 đến gần 1 . Điều này chứng tỏ thang đo dùng để đo lường mức độ thay đổi hoạt động giảng dạy của giảng viên là tốt.

- Về chuẩn bị nội dung giảng dạy (hình 3): gồm 5 nội dung được thể hiện ở đây gồm:
Giảng viên có thông tin về mục tiêu và chương trình học, chuẩn bị tài liệu giảng dạy, chuẩn bị các tiêu chí kiểm tra đánh giá, nội dung giảng dạy bám sát mục tiêu và nội dung môn học, giảng viên có cập nhật kiến thức và liên hệ thực tế và mức độ hiểu bài của người học. So sánh kết quả thu thập được của 3 năm học: 2013 - 2014, 2014 - 2015 và 2015-2016 cho thấy có sự thay đổi trong việc chuẩn bị phương pháp giảng dạy của giảng viên, đặc biệt 2 nội dung được người học có sự thay đổi tích cực là việc giảng viên thông tin đến người học mục tiêu và nội dung chương trình học, việc chuẩn bị tiêu chí kiểm tra và đánh giá trong 2 năm gần đây có sự thay đổi rõ rệt. Các tiêu chí trên có số điểm trung bình từ 3.03 điểm đến 4.23 , sai số chuẩn $<0.04$ và độ lệch chuẩn từ 0.78 đến xấp xỉ 1 điểm. Vì vậy, có thể nói người học đánh giá cao việc chuấn bị, nội dung giảng dạy của giảng viên ở mức độ tốt (hình 3).

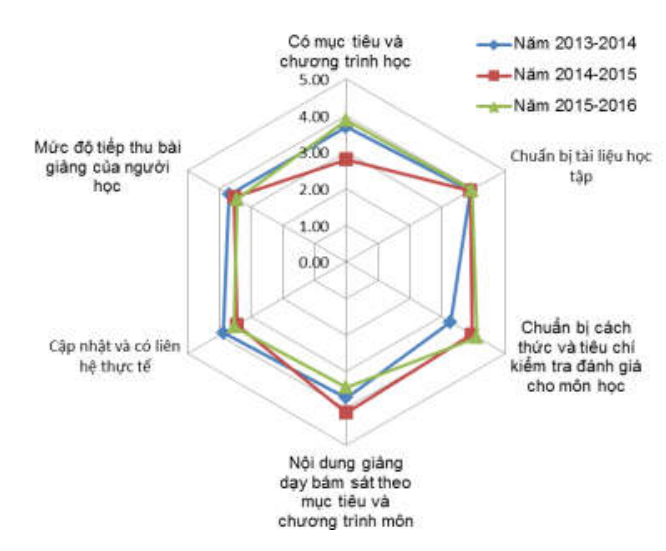

Hình 3. Mức độ thay đổi trong công tác chuẩn bị cho hoạt động giảng dạy của giảng viên.

- Về phương pháp giảng dạy (hình 4): gồm 4 nội dung là: Giảng viên sử dụng phương pháp dạy học tích cực. Tiêu chí này có số điểm trung bình từ 3.15 điểm đến 4.03 , sai số chuẩn $<0.04$ và độ lệch chuẩn từ 0.87 đến xấp xỉ 0.93 điểm. Vì vậy, có thể nói người học đánh giá việc thay đồi phương pháp giảng dạy của giảng viên khá tốt nhưng nhìn chung so sánh 3 năm học thì việc hướng dẫn tự học và tự nghiên cứu có chiều hướng không phát triển (hình 4). 


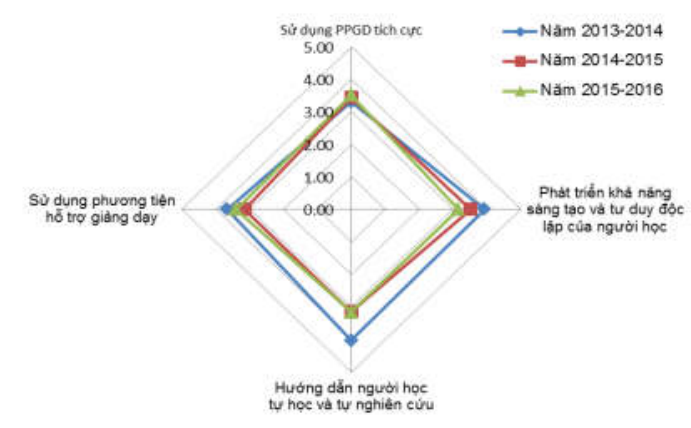

Hình 4. Mức độ thay đổi về phương pháp giảng dạy.

- Về thực hiện quy chế và tác phong sư phạm của giảng viên (hình 5): gồm 6 nội dung như: giảng viên đảm bảo giờ lên lớp, thực hiện đúng số tiết quy định; thực hiện quy chế giảng dạy khách quan và đúng quy chế. Ngoài ra, troong quá trình giảng viên nhiệt tình, trách nhiệm, lắng nghe ý kiến người học, có sự tương tác giữa giảng viên và người học; tổ chức và quản lý lớp học; trang phục lên lớp đúng mực. Trong nội dung này điểm trung bình là 2.74 điểm đến 4.11 điểm, độ lệch chuẩn 0.64088 và sai số nhóm 0.02345 . Vì vậy có thể nói người học phản hồi việc thay đổi hoạt động thực hiện quy chế và tác phong sư phạm của giảng viên ở mức độ khá tốt.

Ngoài ra, nghiên cứu tiến hành gom biến theo 3 nhóm để đánh giá mức độ sự thay đổi hoạt động giảng viên theo 3 nhóm bao gồm: sự chuẩn bị giảng dạy; phương pháp giảng dạy và việc thực hiện quy chế giảng dạy và tác phong sư phạm. Cụ thể đối với từng nhóm như sau:

+ Nhóm 1: Chuẩn bị công tác giảng dạy gồm 5 tiêu chí đánh giá được mã hóa từ $\mathrm{CB} 1$ đến CB5.
+ Nhóm 2: Phương pháp giảng dạy gồm 4 tiêu chí được mã hóa từ PP6 đến PP10.

+ Nhóm 3: Thực hiện quy chế và tác phong sư phạm gồm 6 tiêu chí mã hóa từ QC11 đến QC16.

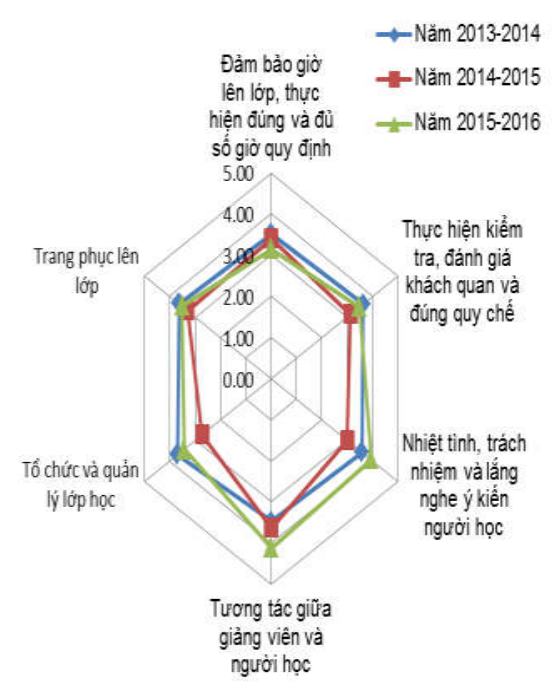

Hình 5. Mức độ thay đổi trong việc thực hiện quy chế và tác phong sư phạm của giảng viên.

Thông qua kết quả bảng.1, chúng tôi thấy rằng sinh viên ở 5 ngành đào tạo đang xét cơ bản đồng ý về sự chuẩn bị nội dung giảng dạy, phương pháp giảng dạy và việc thực hiện quy chế, tác phong sư phạm của giảng viên có điềm trung bình $>3.0$ điểm. Vì vậy, có thể nói người học đánh giá việc thay đổi vế hoạt động giảng dạy của giảng viên chuẩn bị, nội dung và phương pháp giảng dạy của giảng viên ở mức độ khá tốt. Tuy nhiên, so sánh kết quả 3 năm học thì sự thay đổi trong hoạt động giảng dạy của giảng viên không đáng kể.

Bảng 1. Đánh giá điểm trung bình và độ lệch chuẩn các nội dung liên quan đến hoạt động giảng dạy

\begin{tabular}{rlcccc}
\hline STT & Nội dung & Mean & Std. Error & Std. Deviation & N \\
\hline 1 & Tiêu chí 1: Sự chuẩn bị công tác giảng dạy & 3.6801 & 0.01553 & 0.35609 & 526 \\
2 & $\begin{array}{l}\text { Tiêu chí 2: Phương pháp giảng dạy } \\
\begin{array}{l}\text { Tiêu chí 3: Thực hiện quy chế và tác phong } \\
\text { sư phạm }\end{array}\end{array}$ & 3.4514 & 0.01651 & 0.37859 & 526 \\
\hline
\end{tabular}




\section{Kiểm định thang đo bằng $\mathrm{CFA}$ và kiểm định giả thuyết}

Sau khi phân tích nhân tố khám phá EFA các thành phần còn lại trong nghiên cứu gồm 12 biến được chia thành 2 nhóm. Thang đo còn lại thể hiện cho sự phản hồi gồm 4 biến thể hiện quasự thay đổi phương pháp giảng dạy, nhóm nghiên cứu tiếp tục dùng phân tích CFA để khẳng định một lần nữa kết quả EFA là đáng tin cậy hay không?

Kết quả CFA cho thấy mô hình có 101 bậc tự do, chi-square $=1160.866(\mathrm{p}$-value $=0.000<$ 0.05 ), chi-square/ df $=11.494$, GFI $=0.768$, RMSEA $=0.141$ tất cả các trọng số đã chuẩn hóa đều cao $>0.5$ và có ý nghĩa thống kê 0.000 . Do đó mô hình đạt đến sự hội tụ, hệ số tương quan của các biến quan sát đều nhỏ hơn 1 nên đạt tính nguyên đơn. Vì vậy có thể kết luận rằng các khái niệm đạt giá trị phân biệt. Từ đó chứng tỏ mô hình hoàn toàn phù hợp với dữ liệu thu thập được. Chúng tôi tiến hành kiểm định trên số lượng mẫu 526, với độ tin cậy $95 \%$. Giá trị của kiểm định $\mathrm{t}$ về giá trị mức độ sự thay đổi về hoạt động giảng dạy môn học của giảng viên là $>150$ ứng với mức ý nghĩa là 0.000 (Hình 6).

Theo kết quả của bảng kiểm định thống kê 2, chúng tôi có thể kết luận rằng điểm trung bình mức độ thay đổi hoạt động giảng dạy môn học của giảng viên trên 3.0 điểm, chứng tỏ mức độ tương đối về sự hoạt động giảng dạy môn học của giảng viên ở mức tương đối (xấp xỉ 3.45 điểm).

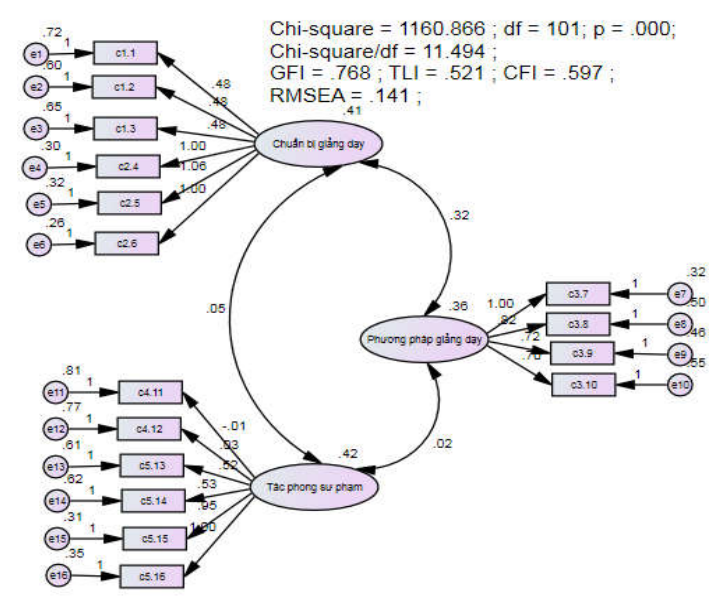

Hình 6. Mô hình CFA đã chuẩn hóa thể hiện sự phản hồi của $\mathrm{SV}$.

Sau khi tiến hành kiểm định giả thuyết nghiên cứu tìm hiểu sự tương quan của các biến số trong mô hình, kết quả thu được như sau: Sự thay đổi phương pháp giảng dạy có mối tương quan thuận với việc chuẩn bị giảng dạy của giảng viên và được giải thích do $52,3 \%$ là do sự chuẩn bị cho việc giảng dạy của giảng viên. Sự phản hồi của sinh viên về việc thực hiện quy chế và tác phong sư phạm có ảnh hưởng đến việc phương pháp giảng dạy và được giải thích do 43,1\%. Tóm lại sự thay đổi phương pháp giảng dạy phụ thuộc vào sự chuẩn bị cho giảng dạy và việc thực hiện quy chế giảng dạy (Bảng 3).

Bảng 2. Kiểm định giả thuyết dựa trên giá trị trung bình của tổng thể One-Sample Test

\begin{tabular}{|c|c|c|c|c|c|c|}
\hline \multicolumn{7}{|c|}{ One-Sample Test } \\
\hline & \multicolumn{6}{|c|}{ Test Value $=0$} \\
\hline & \multirow[b]{2}{*}{$\mathrm{t}$} & \multirow{2}{*}{ df } & \multirow{2}{*}{$\begin{array}{l}\text { Sig. (2- } \\
\text { tailed) }\end{array}$} & \multirow{2}{*}{$\begin{array}{l}\text { Mean } \\
\text { Difference }\end{array}$} & \multicolumn{2}{|c|}{$95 \%$ Confidence Interval of the Difference } \\
\hline & & & & & Lower & Upper \\
\hline $\begin{array}{l}\text { Chuẩn } \\
\text { giảng dạy }\end{array}$ & $\begin{array}{l}237.0 \\
25\end{array}$ & 525 & .000 & 3.68008 & 3.6496 & 3.7106 \\
\hline $\begin{array}{l}\text { Phương pháp } \\
\text { giảng dạy }\end{array}$ & $\begin{array}{l}209.0 \\
80\end{array}$ & 525 & .000 & 3.45136 & 3.4189 & 3.4838 \\
\hline $\begin{array}{l}\text { Thực hiện quy } \\
\text { chế và tác } \\
\text { phong sư phạm }\end{array}$ & $\begin{array}{l}225.5 \\
18\end{array}$ & 525 & .000 & 3.46800 & 3.4378 & 3.4982 \\
\hline
\end{tabular}


Bảng 3. Sự tương quan giữa các biến số trong nghiên cứu đánh giá sự hài lòng

\begin{tabular}{lllll}
\hline & & $\begin{array}{c}\text { Sự chuẩn bị } \\
\text { giảng dạy }\end{array}$ & $\begin{array}{c}\text { Phương pháp } \\
\text { giảng dạy }\end{array}$ & $\begin{array}{l}\text { Thực hiện quy chế và tác } \\
\text { phong sư phạm }\end{array}$ \\
\hline \multirow{2}{*}{ Sự chuẩn bị giảng dạy } & $\begin{array}{l}\text { Pearson } \\
\text { Correlation } \\
\text { Sig. (2-tailed) }\end{array}$ & 1 & $0.523^{* *}$ & $0.431^{* *}$ \\
& $\begin{array}{l}\text { Pearson } \\
\text { Phương pháp giảng dạy }\end{array}$ & $0.523^{* *}$ & .000 & .000 \\
& $\begin{array}{l}\text { Correlation } \\
\text { Sig. (2-tailed) }\end{array}$ & .000 & & $0.553^{* *}$ \\
Thực hiện quy chế và & $\begin{array}{l}\text { Pearson } \\
\text { Correlation }\end{array}$ & $0.431^{* *}$ & $0.553^{* *}$ & .000 \\
tác phong sư phạm & Sig. (2-tailed) & .000 & .000 & 1 \\
\hline
\end{tabular}

**. Correlation is significant at the 0.01 level (2-tailed).

\section{Kết luận và kiến nghị}

Qua kết quả nghiên cứu mức độ thay đổi hoạt động giảng dạy môn học của giảng viên trong thời gian 3 năm học, có thể rút ra kết luận về mức độ thay đổi của hoạt động giảng dạy môn học của giảng viên có sự thay đồi tuy nhiên mức độ chưa cao. Ngoài ra, sự chuẩn bị cho công việc giảng dạy và việc thực hiện quy chế và tác phong sư phạm của giảng viên có mối liên quan rất chặt chẽ với việc thay đổi phương pháp giảng dạy của giảng viên vì vậy người dạy cần quan tâm đến các nội dung nhiều hơn. Hơn nữa, theo kết quả thu được cho thấy việc sử dụng phương tiện công nghệ thông tin, cách kiểm tra và đánh giá kết quả học tập và nội dung chương trình tiếp cận thực tế kém phát tiển do đó nhóm nghiên cứu có một số đề xuất kiến nghị sau:

\section{Một số kiến nghị đáp ứng sự phản hồi của người học}

1. Phát huy tối ưu của việc sử dụng ứng dụng công nghệ thông tin

Đổi mới phương pháp dạy học nâng cao chất lượng giáo dục là một trong những mục tiêu quan trọng hiện nay của ngành giáo dục nói chung và của trường Đại học Sài Gòn nói riêng. Việc ứng dụng công nghệ thông tin nhằm đồi mới nội dung, phương pháp dạy học là một công việc lâu dài, khó khăn đòi hỏi rất nhiều điều kiện về cơ sở vật chất, tài chính, năng lực của đội ngũ giáo viên. Với khả năng sư phạm vốn có cộng thêm một ít bồi dưỡng về kiến thức tin học, các giảng viên hoàn toàn có thể thiết kế được bài giảng điện tử để thể hiện tốt hơn phương pháp sư phạm, góp phần đổi mới phương pháp giảng dạy. Việc sử dụng ứng dụng công nghệ thông tin giúp giảng viên tương tác tốt với công nghệ thông tin và truyền thông khi giảng bài trên lớp, giảng viên có thể chia sẻ và sử dụng những tài liệu đã dạy...giúp giảm thiểu đáng kể khối lượng công việc và tạo hứng thú cho giảng viên thay đổi phương pháp sư phạm và sử dụng công nghệ thông tin nhiều hơn, khuyến khích nâng cao chuyên môn... Đối với người học sẽ nâng cao hứng thú và động lực học tập, tạo cơ hội tốt hơn để sinh viên tham gia và hợp tác cùng nhau, phát triển kỹ năng giao tiếp và tự học, tự nghiên cứu, sinh viên cũng có thể xử lý và nắm bắt được nhiều thông tin thông qua bài giảng rõ ràng, hiệu quả và linh hoạt. Giúp sinh viên trở nên sáng tạo và tự tin hơn khi thuyết trình trước lớp.

2. Đổi mới đánh giá kết quả học tập thông qua việc thi, kiểm tra học phần

Kết quả học tập của một sinh viên được hình thành từ kết quả học tập của từng môn học (học phần). Theo qui chế hiện hành, việc đánh giá kêt quả học tập của từng môn học được thực hiện thông qua các hình thức: thi viết (trắc nghiệm hoặc tự luận), vấn đáp, làm thực tập hoặc kết hợp giữa các hình thức trên. Việc áp dụng hình thức nào phụ thuộc vào điều kiện giảng viên, vào tính chất của từng môn học và 
vào mục tiêu được đặt ra đối với môn học. Để nâng cao tính chính xác và khách quan của việc đánh giá kết quả học tập và đảm bảo yêu cầu đào tạo của nhà trường, Trường Đại học Sài Gòn đã có những đổi mới, hoàn thiện các biện pháp đánh giá kết quả học tập trong sinh viên như:

+ Sử dụng ngân hàng đề thi. Đảm bảo người dạy không cắt xén chương trình và người học không học tủ, học trọng tâm và đảm bảo tính khách quan, vô tư trong thi cử.

+ Thường xuyên thay đổi bộ đề thi, đổi mới cách ra đề thi để đảm bảo tính chính xác, tính thời sự của đề thi và hạn chế việc sinh viên tự thu thập đề thi và giải trước.

Nên thay đổi cách thức ra đề thi đó là các đề thi viết không chỉ giới hạn ở các đề tự luận như trước mà được thiết kế bằng sự kết hợp giữa tự luận, trắc nghiệm tự luận và giải quyết tình huống. Đối với hầu hết các môn học đề thi nên được cấu tạo bởi hai phần: Lý thuyết và bài tập. Ở phần lý thuyết các câu hỏi đưa ra là câu hỏi tự luận hoặc/và câu hỏi trắc nghiệm tự luận (câu hỏi đúng sai có giải thích vì sao). Phần bài tập là một hoặc nhiều tình huống yêu cầu giải quyết. Cách ra đề thi như trên đã giải quyết được những hạn chế của bài thi viết thuần tuý tự luận đòi hỏi sinh viên có sự ứng dụng các kiến thức lí luận trong việc giải quyết các tình huống cụ thể tránh tình trạng học vẹt.

3. Xây dựng chương trình đào tạo và nội dung môn học tiếp cận thực tiễn

Nhược điểm đó là hệ thống và các chương trình giáo dục và đào tạo của các trường hiện nay là quá nặng về phân tích lý thuyết, không định hướng thực tiễn và hành động, thiéu và yếu trong phát triển kỹ năng quan hệ qua lại giữa các cá nhân, thiển cận, hạn hẹp, không có tiếp cận toàn diện tổng thể trong những giá trị và tư duy của nó và chưa giúp người học làm việc tốt trong các nhóm cũng như chưa có kỹ năng tự phát triển. Trên cơ sở đó nhóm nghiên cứu đề xuất là cần: "Thiết kế các chương trình giáo dục và đào tạo chú trọng định hướng kết quả đầu ra và định hướng năng lực" có thể xem là một giải pháp để giải quyết khắc phục nhược điểm trên.
Việc thực hiện xây dựng chương trình và nội dung môn học có thể theo 2 cách như sau:

Từ trên xuống: với giả định đã có chuẩn đầu ra, trên cơ sở ta xác định khối lượng kiến thức, kỹ năng và thái độ cần thiết cho sinh viên. Từ đó, phân chia các khối kiến thức trong một dây chuyển tích hợp vào các môn học những năng lực cần thiết của ngành nghề đào tạo. Do đó, chúng ta từ chuẩn đầu ra chung của cả chương trình học xác định thành cấu trúc chương trình đào tạo, từ đó xác định chuẩn đầu ra cho từng môn học và từ đó xạy dựng đề cương chi tiết cho từng môn học.

Từ dưới lên: với hiện thực chúng ta đã có chương trình đào tạo cụ, với đề cương chi tiết của các môn học cũ̃ nhưng sự liên kết giữa các môn chưa được xác định rõ, chuẩn đầu ra của từng môn chưa được xác định. Với tình huống này, chúng ta xác định lại chuẩn đầu ra của từng môntrong sự so sánh với chuẩn đầu ra của ngành đào tạo. Thông qua đó xác định chuỗi liên kết của các môn và trên cơ sở đó hiệu chỉnh lại đề cương chi tiết cũ hình thành đề cương chi tiết mới.

Chương trình dạy học định hướng kết quả đầu ra không quy định những nội dung dạy học chi tiết mà quy định những kết quả đầu ra mong muốn của quá trình đào tạo, trên cở sở đó đưa ra những hướng dẫn chung về việc lựa chọn nội dung, phương pháp, tổ chức và đánh giá kết quả dạy học nhằm đảm bảo thực hiện được mục tiêu dạy học tức là đạt được kết quả đầu ra mong muốn. Trong chương trình dựa trên kết quả đầu ra, mục tiêu học tập, tức là kết quả học tập mong muốn thường được mô tả thông qua các thuộc tính nhân cách chung (Attributes) và các kết quả yêu cầu cụ thể (Outcomes) hay thông qua hệ thống các năng lực (Competency). Kết quả học tập mong muốn được mô tả chi tiết và có thể quan sát, đánh giá được. HS cần đạt được những kết quả yêu cầu đã quy định trong chương trình. Việc đưa ra các chuẩn đào tạo cũng là nhằm đảm bảo quản lý chất lượng giáo dục theo định hướng kết quả đầu ra.

Tóm lại: Với những khuyến nghị trên xuất phát từ sự đánh giá thay đổi về hoạt động giảng dạy môn học, những khuyến nghị này sẽ được 
các nhà quản lý và giảng viên nghiên cứu và xem xét chọn lọc ứng dụng để nâng cao chất lượng giảng dạy và đào tạo.

\section{Tài liệu tham khảo}

[1] Vũ Thị Phương Anh (2005), Thực hiện thu thập và sử dụng ý kiến sinh viên trong đánh giá chất lượng giảng dạy: Kinh nghiệm từ Đại học Quốc gia TP. Hồ Chí Minh, Giáo dục đại học chất lượng và đánh giá, tr48-63, Nhà Xuất bản Đại học Quốc gia Hà Nội năm 2005.

[2] Nguyễn Kim Dung (1999), Khảo sát khả năng có thể sử dụng ý kiến phản hồi của sinh viên trong trường ĐHSP Tp.HCM.

[3] Nguyễn Kim Dung (2010), “Khảo sát mức độ hài lòng của sinh viên về chất lượng giảng dạy và quản lý của một số trường ĐH Việt Nam”, Kỷ yếu hội thảo khoa học đánh giá Xếp hạng các trường đại học và cao đẳng Việt Nam, trang 203-209.
[4] Trần Xuân Kiên (2009), Đánh giá sự phản hồi của sinh viên về chất lượng đào tạo tại Trường đại học Kinh tế và Quản trị Kinh doanh đại học Thái Nguyên, Luận văn Thạc sĩ Quản lý giáo dục, Viện Đảm bảo Chất lượng Giáo dục, ĐHQG Hà Nội.

[5] Nguyễn Thị Trang (2010), Xây dựng mô hình đánh giá mức độ hài lòng của sinh viên với chất lượng đào tạo tại Trường Đại học Kinh tế, ĐH đà Nẵng.

[6] Marsh (1984), Students' Evaluation of Educational Qualit y (SEEQ).

[7] March 1987 Students' evaluations of university teaching: Research findings, methodological issues, and directions for future research.

[8] Michele Marincovic (1999), Using Student Feedback to Improve Teaching, Changing Practices in Evaluating Teaching, tr45-tr69.

[9] Murray (1985) classroom teaching behaviors and student ratings of college teaching effectiveness.

\title{
Changes in the Teacher's Teaching Activities: Seen from the Learner's Feedback
}

\author{
Le Chi Lan, Do Dinh Thai \\ Saigon University, 273 An Duong Vuong, Ho Chi Minh City, Vietnam
}

\begin{abstract}
Higher education plays a key role in providing knowledge and skills for students to participate in the labor market. The quality of education has long become a boiling issue for many individuals and organizations concerned. As in higher education, the lecturer's instruction plays a decisive role, the Ministry of Education and Training requires higher education institutions to shift their current teaching activities to the credit-based training system, which inevitably involves the innovated learner-centered teaching approach. This study aims to find out the level of the learner's satisfaction with the teaching methods, the teaching process and the quality of the training process; thereby to identify the learner's expectations regarding the training process.
\end{abstract}

Keywords: Satisfaction, learners, teaching courses, faculty. 